\title{
MEDIA EXPOSURE AND EDUCATION OF FIRST TO SIX GRADE CHILDREN FROM SLOVENIA - PARENT OPINIONS
}

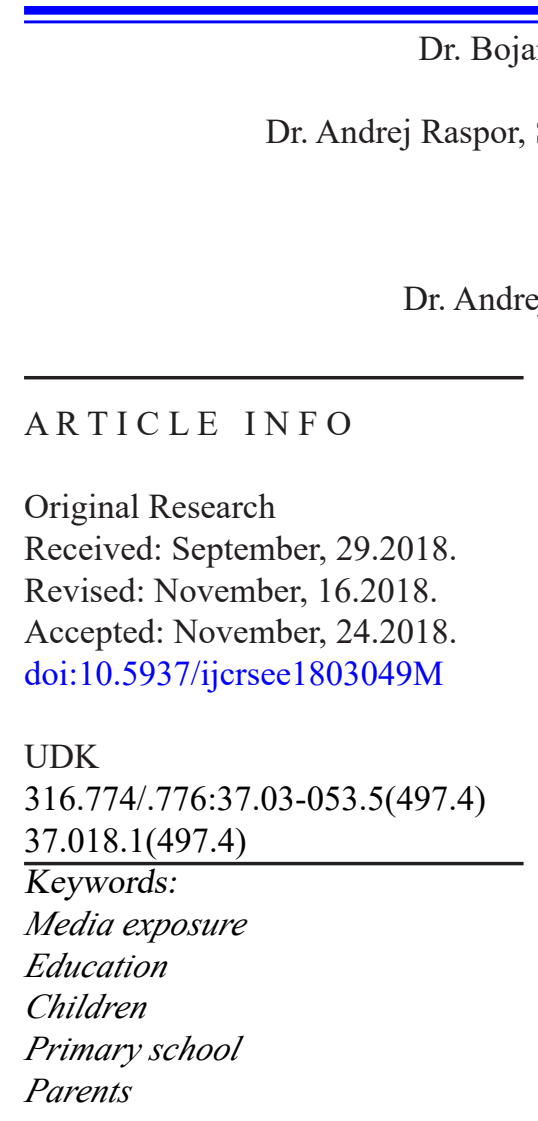

\begin{abstract}
A B S T R A C T
The family environment plays an important role in influencing the way that children use the media and the degree of their exposure to media, however the mediating role of parents in this process is not sufficiently understood. The present paper presents the results of a 2016 Slovenian national survey in which opinions of 2,825 parents concerning their children's exposure to media were collected and analysed using the SPSS PSAW Statistic 18 software package. Our results show that exposure to media by children from the first to the sixth grade increases with age, that children of parents who are themselves heavy media users are more likely to be heavy users and that children who are heavy media users also receive lower test scores.
\end{abstract}

\section{INTRODUCTION}

Contemporary information and communication technologies or devices by which we receive media messages are present on every step of our daily routines and lives. Already radio, then television and today computers, smartphones and other screen media became central nodes of activity in homes around the world, defining family environments. As generations of families inevitably accepted contemporary media as something ordinary and necessary, so concerns have increasingly been raised among parents particularly concerning the influences and effects of contemporary media on their children (Alexander Corresponding Author

Dr. Bojan Macuh, Faculty of Media, Ljubljana, Slovenia E-mail|: bmacuh@gmail.com

This work is licensed under a Creative Commons Attribution - NonCommercial - NoDerivs 4.0. The article is published with Open Access at www.ijcrsee.com

(c) 2018 IJCRSEE. All rights reserved.

2008, 121). "Few would deny that media play a central role in the lives of today's children and adolescents. Their homes, indeed their bedrooms, are saturated with media. Many young people carry miniaturized, portable media with them wherever they go. They comprise the primary audience for popular music; they form important niche audiences for TV, movies, video games, and print media (each of these industries produces extensive content targeted primarily at kids); they typically are among the early adopters of personal computers (indeed, of most new media) and are a primary target of much of the content of the World Wide Web." (Roberts, Foehr, in Rideout $2005,1)$. Parent concerns that media negatively affects children is related to the exponential technological development of contemporary society in which generation live in almost unrecognizably distinct ways. Parents have less knowledge and experience with new media than their children, who are in contact with the media almost since birth and so the parents lose some of control over their children's 
lives. (Valkenburg in Taylor Piotrowski 2017, 250).

\subsection{The family environment}

Studies of the influence of children's exposure to media, particularly screen media, on their physical and psychical development and socialization need to take into account the mediating role of parents and the family context in which the children spend most of the time. In a review of mass communication studies A. Alexander (2008) groups the theoretical and empirical research into several schools of thought with different backgrounds and attitudes towards the into the relationship between media and the family.

Historically most influential were studies in the framework of the social learning theory, a theory of learning and social behaviour, which proposes that new behaviour, can be acquired by observing and imitating others (Bandura 1977, 1994). According to the theory, children and adolescents learn or acquire behaviour and worldviews by imitating role models, which include those seen on $\mathrm{TV}$, especially if the models are appealing or similar to children. The theory was supported by empirical research on the negative influence of television on violence in children (e.g. Bandura, Ross, in Ross 1961). A. Alexander (2008) contextualizes the noted social learning theory within the contemporary social cognitive theory, which aside from the already mentioned role-model imitation also points to the fact that the media can influence children's relationship with the family members as well as apprehension of family roles and family relationships.

The author reviews other theories related to the research into media and family environment such as cultivation theory (Gerbner et al. 1994), which studies long-term effects of individual's exposure to consistent media messages, which over the time leads to the overlapping of individual's world views with those presented in the media. The theory suggests that individuals who are exposed to violence as portrayed in the media may begin to believe that crimes are more common and ever increasing than in reality. It has been shown, however that the real world effect of this hypothesis is minimal (Ferguson 2014, 14).

Children are however not isolated individuals; they are entangled in relationships with other children and adults within families, peer groups and society as a whole. While both of the above mentioned theories focus on effects of media on individuals, the theory of family systems (Baran and Davis 2006) highlights the family as the basic unit of observation and research. The family is here understood as a system of interconnected parts so that changes in one part of the system can lead to changes in other parts. This approach allows the understanding of complex interactions between family members and the family process as a whole while also providing a more nuanced view of both negative and positive effects of media. Family members' interactions form behavioural patterns, including those related to media use, which become habitual in their everyday lives.

Related is another theoretical approach reviewed by A. Alexander (2008), namely the sociocultural approach (Craig 1999; PausHasebrink et al. 2013), which draws attention to the broader cultural patterns of family habits and practices in relation to media use. This approach contextualizes mass media within a symbolical process in which societal reality (re)produces, maintains, rectifies and changes. Indeed, both theoretical (e.g. Alexander 2008; Valkenburg in Taylor Piotrowski 2017) and empirical research points to the fact that family and its socioeconomic and sociocultural context in particular is the most important mediating system of adolescent media use (e.g. Scherr et al. 2018; Roberts, Foehr, in Rideout 2005). A holistic approach to mass media research, particularly the research of the influence of media exposure on the development and socialization of children thus needs to take into account the socioeconomic and cultural contexts of children's family lives.

\subsection{Media exposure effects}

The media have both positive and negative effects on the families and on the relationships between children and parents. Media influences are actually much more complex than entailed in the simple dichotomy between negative and positive effects (Livingstone 2007). Furthermore in the complex tripartite relationship between children, parents and the media, each of these parts may be seen to play the role of a mediator of behaviour. The interactions of family members shape behavioural patterns, which become habits in their everyday lives. In this family process, the contemporary media play a crucial intermediary role as mediators of family interactions as well as purveyors of behavioural patterns seen on the 
International Journal of Cognitive Research in Science, Engineering and Education (IJCRSEE), 6(3), 49-57

media. Parents mediate between the media and the children by setting rules and also by the fact that their own media habits unconsciously affect that of their children. The influence of family environment on the quantity and quality of exposure of children to media has been empirically shown also by extensive research in the United States (Roberts, Foehr, in Rideout 2005). Even children may be considered as mediators of their parents' media use and media-related behaviour. In relation to media education children may change their roles with the parents for example in observed cases when they remind parents of inappropriate media-related behaviour, inappropriate use of media, such as smart phones, in the public or of the parents' refusal to deal with children when the parents are busy or constantly check or reply to electronic messages on their devices (Kalin 2004). Studies show that screen media does also have a significant influence on the children's perception and understanding of family relationships, as they perceive the depictions of families in the media s realistic. Exceptional storytelling power of some contemporary media can, given intensive exposure of individuals, create a sense of social reality, which differs significantly from the reality of the outside world. Screen media, particularly television, often represent central nodes of family environments and the context of family interactions. In the negative sense this may results less personal intimate contacts between parents and children. In the positive sense this may result, on the contrary, to more interaction and more time that parents and children spend together. "/.../ television may serve an almost limitless range of diverse uses and functions. Family members can watch television to be together or to get away from each other; as a basis for talk or to avoid interaction; as a source of conflict, or an escape from it." (Alexander 2008, 133)

Noted positive influences are for example the role that some media may play in encouraging routine family interaction and communication. Co-watching of evening television shows with appropriate entertaining or, even better, educational content should not be considered problematic but in some cases perhaps even encouraged. This is of course not possible when television is present in children's rooms or when children decide to watch television alone. We should also note the educative potential of media for the children with quality educational content related to vocabulary improvement, learning of native and foreign languages, learning about natural and cultural phenomena etc. Furthermore, the media as providers of information may allow families to gain crucial information, parents to be up to date with current events, actively participate in communities and help them with the socialization and education of their children. The media can be considered contemporary social equalizers, assuming that the media providers are readily accessible and affordable to the majority of families (Alexander 2008).

The negative influences of media are much better researched due to the interests and concerns of the general public. To mention only selected, more problematic issues, one of the better-documented is the correlation between exposure of children to media, particularly screen media, and lower physical fitness, higher body weight and obesity among children (Notten, Kraaykamp, in Tolsma 2013; Arango et al. 2014; Rutherford et al. 2015; Robinson et al. 2017). The correlation between media exposure and obesity is not related only to the significant screen time or long-term exposure and consequently a more sedentary lifestyle and physical inactivity of children, but also to exposure to marketing content in media. Television commercials, such as those paid by the fast food industry, often promote an unhealthy lifestyle (Robinson et al. 2017). Particularly worrying is the effect of media exposure on socialization of children as research shows a clear correlation between greater screen time and lesser time of interaction between children (Sigman 2012). Overall, children's involvement in mediated reality does bring challenges regarding their health, eating and sleeping habits, aggressive behaviour, language development, consumerism, building of identity and relationships with others.

Any research of media influence on children and adolescents is challenged by the fact that it is difficult to establish clear cause-andeffect relationships or rather to prove undeniably that media exposure directly influences behavior. Correlation does not necessarily means causation and this is not consistently clear from the published research. When greater and longer exposure to violent content in media coincides with higher crime or delinquency rate among adolescents, the media is not the only and indeed not the most important factor or mediator, rather one cannot solely blame media without considering other factors. As argued in the previous paragraph, it is the family and its socioeconomic and sociocultural position within the broader society that needs to be considered. The influence 
of media on adolescents as family members is to a large extent dependent upon cultural, social and economic dispositions of individuals, families and communities. In other words, family media environment, media availability and use is affected by parent's ethnicity, education, income, etc. as well as adolescent's sex and age (Ferguson 2014; Roberts, Foehr, in Rideout 2005).

\subsection{Parent Mediation}

Parents face their fears concerning the negative effects of contemporary media on their children in several ways. They may limit their children's access to violent or sexual content or limit the time of exposure. This may sometimes lead to conflicts in the family, particularly between parents and their children. Control of time and content that the children are exposed to may be both implicit and explicit which means that it either works according to unwritten rules, such as children's self-control or the rules are set clearly by the parents (Alexander 2008, 133). Setting rules and all other types of control and interventions in relation to children's media exposure is usually called parent mediation (Alexander 2008; Valkenburg in Taylor Piotrowski 2017, 250).

There are no simple and universal solutions and answers to the questions of how the parents should protect their children from potentially harmful effects of exposure to media as the families greatly differ according to a range of cultural, socio-economic, psychological and other factors. Researchers nevertheless suggest two possible mechanisms of protection from harmful effects. (Chakroff in Nathanson 2008). The first is based on the parents' mediation of children's media use by open conversation about the content of media messages as well as about the appropriate time of exposure, the setting of rules to limit the quantity and quality of exposure and with the co-use or rather usually co-watching of the media. The second is based on mediation by the school by which the school introduces media literacy courses in school curricula in order to educate the children about the appropriate use of the media and to prepare them to be critical consumers of media messages.

Researchers who deal with mediation of media exposure empirically (see for example Böcking in Böcking 2009; Schaan in Melzer 2015) separate between active and restrictive mediation. Active mediation encompases open conversation about the media and encourage- ment of critical relation towards media messages. Restrictive mediation is based on the setting of rules about the quantity and quality of exposure as well as the so called co-watching. Some researchers argue that the results of restrictive mediation may often be contraproductive (Chakroff and Nathanson, 2008, 555). Some critical theoretical approaches however reject such understanding of mediation and argue that mediation is merely a remedying measure for the lack of quality family relationships, particularly those between parents and children (ibid. 557). More critical researchers also warn of a theoretical possibility of a counter-effect of teaching media literacy as children which are encouraged to a more detailed and critical treatment of media messages, to which they are exposed to, might better remember, internalize and later live out the violent and other negative messages: " $/ . . . /$ In fact, intervention research is prone to boomerang effects, in which the exact opposite effect of what was intended occurs." (ibid. 558; Valkenburg in Taylor Piotrowski 2017, 250). Such theoretical concerns don't mean however, that media literacy education is not desired or even necessary, but they draw attention to the complexity of this research field and call for further empirical research with which to test different theoretical assumptions concerning exposure of children to media.

\subsection{Comparable research}

Comparable extensive, though somewhat outdated and geographically distant is the study of exposure to media published by (Roberts, Foehr, in Rideout 2005). The study encompasses a broader population of children and teenagers aged 8-18 years of which the younger group aged 8-10 is comparable to our research. The average exposure to television and other screen media, except computer, in this group was as much as 4:41 hours (ibid. tab. 4-A) in which the exposure was largely dependent upon the family ethnicity so that African-American children were exposed the most and Caucasian children the least (tab. 4-B). Exposure to computer in the same age group was 0:37 hours (ibid. tab. 4-J), while exposure to video game consoles was 1:05 hours. Books, magazines, newspapers and other printed media is used by the children in this age group for 0:44 hours on average (tab. 4-E), more in families of parents with higher education (tab. 4-F), while radio and other audio media are used for 0:59 hours on average 
International Journal of Cognitive Research in Science, Engineering and Education (IJCRSEE), 6(3), 49-57

(tab. 4-G), more by girls than boys (tab. 4-H). The exposure to all media in this age group amounts to as much as 5:52 hours (tab. 5-A) on average, thus about 6 hours which surprisingly represents a quarter of the day and roughly more than a third of the day spent not sleeping. If we compare this research to our own we find out that more than a decade ago American children were exposed to different media about two times as much as primary school children in Slovenia. It should be pointed out however that a large percentage of children multitask, meaning they use multiple media or rather media devices simultaneously. The total exposure time is thus possibly significantly lower (Roberts, Foehr, in Rideout 2005, 36). Percentages of use of individual media by children in the noted research are $55 \%$ for television and related media, $14 \%$ for radio and other audio media, 7\% for desktop and tablet computers, $12 \%$ for printed media and $12 \%$ for gameplay on the video game consoles (tab. 5-C). The study also underlines the facts that children with personal devices or devices which are present in their own rooms are exposed much longer on average (tab. 6-A), that lower exposure time correlates with rulesetting by their parents (tab. 6-B) and that the overall media environment influences the children's exposure to media (tab. 6-C): "Clearly, in homes where the TV plays a central role in defining the environment, all media exposure increases." (Roberts, Foehr, in Rideout 2005, 46). The authors argue that "the amount of time young people have available to devote to media seems to have reached some kind of ceiling, but the amount of media messages to which they are exposed apparently has not. Kids seem to be engaging one, two, three, or more media simultaneously - or at least in a manner that looks simultaneous. Whether the consequences of such media behavior are good, bad, or neutral remains an open question." (Roberts, Foehr, in Rideout 2005, 55)

An updated study by the same authors (Rideout, Foehr, in Roberts 2010) produces roughly similar results while the screen-time or rather the time of exposure to screen media for children greatly increased. In their first study from 1999. the total daily media exposure time was 6:19 hours, in 2004 it was 6:21 while in 2009. it was already 7:38, amounting to almost half of the day not spent sleeping. These numbers account for multitasking. Despite the fact that the authors in their previous study supposed that the total daily exposure time already reached maximum levels, as cited in the previous paragraph, the exposure time continues to rise and it seems that it can potentially cover the whole children's leisure time at least for those most exposed. This does or will in the near future undoubtedly have repercussions for the quality and quantity of interactions between children and parents as well as children and their peers and on children's socialization.

From Europe the best and most up-todate comparison to our research is the annual report of media exposure by the British government agency Ofcom („Ofcom“ 2014). Last year's report for age group 8-11 years shows that $39 \%$ of children own personal mobile phones, $52 \%$ own tablet computers, $95 \%$ watches TV programs for two hours per day on average. Fifty two percent of children watches TV programs on the tablet computer. Eighty-five percent of children play computer games for an hour and a half per day on average. Ninety-five percent of children surf on the internet and are exposed to internet content for about two hours a day, among these $46 \%$ use the internet via the computer while $22 \%$ use it on their mobile phones. YouTube is the most popular internet site and is used every day by as much as $81 \%$ of children. Twentythree percent of children aged 8-11 also has an active profile on social media (Ofcom 2016).

\section{MATERIALS AND METHODS}

In 2016. we conducted a national survey, collecting opinions of parents regarding first to sixth grade school children's media exposure and habits. A total of 62 school participated in the survey. Data was collected using online questionnaires, where links were sent to parents from randomly selected classes. In total 2,825 parents of first to sixth grade children (ages 6-12) were included in the survey. Subjects participated voluntarily and were not financially compensated, as their participation was anonymous, not involving a name or any identifiable information about subjects. We monitored the process using IP tracking and Google forms. Schools were located in all geographical regions with equal divide among rural and urban population.

Research sample of parents resembles according to the age (average $40 \mathrm{SD}=5$ years). $54 \%$ of children lived in 4 member households, $54 \%$ lived in rural areas. Parents opinions were in $51 \%$ for male gender (boys). Thirteen percent of children were in shared custody. Age and geographical location of families and as so children were controlled so that the sam- 
ple was not additionally adjusted (weighted). Parents who responded to the survey questions were about evenly distributed in two age groups of 1-to-3-grade children (6-9 years) and 4-to-6-grade children (10-12 years). The questionnaire consisted of 54 variables plus 14 demographic. Questions regarding opinions were gathered using 5-item Likert scale (1-never to 5-always). Media exposure was measured as total daily exposure time on each device/media. These data were than grouped in later analysis.. Internal consistency of the questionnaire was high: Cronbach alpha was 082 for media exposure subscale an 0,71 for opinions subscale. We analysed the data using SPSS PSAW Statistic 18.

Among the goals of this research, was to collect data on media exposure of the two age groups of children, presence and usage of different devices and information sharing. In addition a special focus was on parents as media limitators and educators. As such the following hypotheses were structured:

Hypothesis 1 (H1): Child's exposure to media increases with age (1-3 grade in comparison to 4-6 grade)

Hypothesis 2 (H2): Parents who are heavy media users cause that their children are more likely to be heavy users as well

Hypothesis $3(\mathrm{H} 3)$ : 4-6 grade children who are heavy media users have lower grades in school (1-3 grade children are not graded and were therefore not analysed)

\section{RESULTS}

Electronic devices in children's rooms (controlled by children) of 1-6 grade children in Slovenia are not low. Only 16,5\% of children aged 6-to-12-years old have a TV set in their room. Every third child has a radio and $38 \%$ has their own PC or tablet. $43 \%$ of children have personal owned device that connects to the internet and every other child has their own mobile phone. One in six has it own game console. Although there are not large differences in owning the devices between the age groups there are substantial differences in the exposure times. These differences can be clearly seen on Table 1 .
Table 1. Average media exposure times of the two age groups (in minutes daily) on different media.

\begin{tabular}{|c|c|c|c|c|c|c|c|}
\hline & $\begin{array}{l}\text { Using TV } \\
\text { device } \\
\text { (television, } \\
\text { video, games } \\
\text { and other) }\end{array}$ & Radio & $\begin{array}{c}\text { Computer } \\
\text { or tablet }\end{array}$ & $\begin{array}{l}\text { Mobile } \\
\text { phone } \\
\text { for all } \\
\text { activities }\end{array}$ & $\begin{array}{c}\text { Printed } \\
\text { media }\end{array}$ & $\begin{array}{c}\text { Game } \\
\text { console } \\
\text { with } \\
\text { screen }\end{array}$ & $\begin{array}{l}\text { Sum of } \\
\text { all } \\
\text { media } \\
\text { devices } \\
\text { usage }\end{array}$ \\
\hline $\begin{array}{l}\text { 1- to 3- } \\
\text { grade- } \\
\text { children }\end{array}$ & 66 & 21 & 29 & 13 & 23 & 4 & 156 \\
\hline $\begin{array}{l}\text { 4- to 6- } \\
\text { grade } \\
\text { children }\end{array}$ & 78 & 26 & 43 & 38 & 25 & 9 & 219 \\
\hline $\begin{array}{c}\text { Both } \\
\text { groups } \\
(1-6 \\
\text { grade }) \\
\end{array}$ & 71 & 23 & 35 & 23 & 24 & 6 & 182 \\
\hline
\end{tabular}

The most commonly used media device for both age groups is still TV (due to large screen) as on average 6 to 12 year olds (both age groups) spent more than an hour daily. Total media exposure times are about 3 hours daily. We used the independent t-test to analyse H1 (differences between the mean exposure of two independent age groups). It was assumed the sampling distribution of differences between means is normally distributed in the population. For the following t-tests the assumption of homogeneity of variance has been violated, and the Equal variances not assumed t-test statistic was used for evaluating the null hypothesis of equality of means. There are significant differences in media exposure between the two age groups (1-3 grade and 3-6 grade).

- Total media exposure: $\mathrm{t}(\mathrm{df}=2811)=$ $-9,385 \mathrm{p}<.001$. The mean values indicate that younger children are less exposed all media $(\mathrm{M}=156)$ than older $(\mathrm{M}=219)$.

- TV device: $\mathrm{t}(\mathrm{df}=2782)=-5,718, \mathrm{p}<$ .001 . The mean values indicate that younger children are less exposed to TV $(\mathrm{M}=66)$ than older $(\mathrm{M}=78)$.

- Radio: $\mathrm{t}(\mathrm{df}=2569)=-2.573, \mathrm{p}<.01$. The mean values indicate that younger children $(M=21)$ listen to the radio less than older $(\mathrm{M}=26)$.

- Computer or tablet: $\mathrm{t}(\mathrm{df}=2710)=$ $-8,661, \mathrm{p}<.001$. The mean values indicate younger children $(\mathrm{M}=29)$ are less exposed to computer or tablet then older $(\mathrm{M}=43)$.

- Mobile phone - $t(\mathrm{df}=2678)=-15,008$, $\mathrm{p}<.001$. The mean values indicate younger children use substantially less mobile phones $(\mathrm{M}=13)$ then older $(\mathrm{M}=38)$.

- Printed media: $t(d f=2627)=-1,507$, $\mathrm{p}>.05$. No significant differences between the two groups.

- Game console with own screen: $\mathrm{t}(\mathrm{df}=$ $2576)=-4,382, p<.001$. The mean values indicate younger children $(\mathrm{M}=4)$ use less video games console with screen then older $(\mathrm{M}=9)$. 
To test $\mathrm{H} 2$ parents and children were divided into three groups similar in numbers (border framework 33 and 66 percentiles) into small medium and heavy media users. The results of the $3 \times 3$ analysis design can be seen on Table 2.

Table 2. Media exposure times of small, medium and heavy media users parents in comparison to small medium and heavy media children in minutes of daily use and the percentage of all*

\begin{tabular}{|c|c|c|c|c|}
\hline & $\begin{array}{c}\text { Children } \\
\text { small } \\
\text { media } \\
\text { users }\end{array}$ & $\begin{array}{c}\text { Children } \\
\text { medium } \\
\text { media } \\
\text { users }\end{array}$ & $\begin{array}{c}\text { Children } \\
\text { heavy } \\
\text { media } \\
\text { users }\end{array}$ & Total \\
\hline $\begin{array}{l}\text { Parents } \\
\text { small } \\
\text { media } \\
\text { users } \\
\end{array}$ & $\begin{array}{c}63 \\
(11 \%)\end{array}$ & $\begin{array}{c}131 \\
(11 \%)\end{array}$ & $271(6 \%)$ & 132 \\
\hline $\begin{array}{l}\text { Parents } \\
\text { medium } \\
\text { media } \\
\text { users }\end{array}$ & $66(9 \%)$ & $\begin{array}{c}135 \\
(12 \%)\end{array}$ & $\begin{array}{c}303 \\
(16 \%)\end{array}$ & 189 \\
\hline $\begin{array}{l}\text { Parents } \\
\text { heavy } \\
\text { media } \\
\text { users }\end{array}$ & $64(9 \%)$ & $\begin{array}{c}133 \\
(12 \%)\end{array}$ & $\begin{array}{c}331 \\
(14 \%)\end{array}$ & 195 \\
\hline
\end{tabular}

To test the hypothesis $\mathrm{H} 2$ we used chisquare and found significant differences between groups; chi square $(4)=120,611$ at $\mathrm{p}<.000$. The difference can be seen that there are only $6 \%$ of children that are heavy media users where at the same time parents are light media users. In contrast there are $14 \%$ of heavy users children in a heavy users parents group. This confirms that when parents are heavy media users this has an effect that their children are far more likely to be in the same group.

Finally for $\mathrm{H} 3$ we used the analysis of variance to test if 4-6 grade children's media exposure has an effect on school grades (ANOVA). Grades in Slovenia are 1 to 5 where 5 is excellent. We found that significant differences between the grades of small, medium and heavy media users $\mathrm{F}(2,1161)=16,760$, $\mathrm{p}<0,001$. Post hoc Scheffe showed significant differences between children who are heavily exposed and other two groups. Average mark of light users was 4,67, medium was 4,66 and heavy was 4,46 . The difference is small, however we have to consider very high average marks in grades 4 to 6 and that the difference of 0,21 represents a $4,7 \%$ difference. It seem that being a heavy user child already in these first years of education has an effect on school average academic performance.

\section{DISCUSSION AND CONCLUSIONS}

The family environment plays an important role in influencing the way that children use the media and the degree of their exposure to media, however the mediating role of parents in this process is not sufficiently understood. The present paper presents the results of a 2016 Slovenian national survey in which opinions of 2,825 parents concerning their children's exposure to media were collected and analysed using the SPSS PSAW Statistic 18 software package. Our results show that exposure to media by children from the first to the sixth grade increases with age, that children of parents who are themselves heavy media users are more likely to be heavy users and that children who are heavy media users also receive lower test scores.

The following hypotheses have been structured, from which we determine:

H1: There are significant differences in media exposure between the two age groups (1-3 grade and 3-6 grade).

H2: Confirms that when parents are heavy media users this has an effect that their children are far more likely to be in the same group.

H3: It seem that being a heavy user child already in these first years of education has an effect on school average academic performance.

From the collected results we can conclude that family has a very important impact on whether or how children use the media as part of their free time and also for the needs of the school work.

In this regard, we would like to point out that in this context the role of parents or family is not clearly defined. Children often use the media and are at the same time exposed to potential exploitation of the media for marketing purposes. Of course, parents are not aware of this directly, since they are also the users of the media themselves, but the media affects them less, since they can reasonably decide what is good for them and what is not.

We can conclude that the media are an integral part of the educational process of children in elementary school and also in further education, and despite some negative conse- 
quences that the media can have on children, the media is an important element in achieving better academic achievements.

\section{ACKNOWLEDGEMENTS}

Data collection process was supported by Slovenian Research Agency, in the framework of Infrastructure program of the Faculty of Media - Collecting, Managing and Archiving Data on Media Literacy (contract number: 1000-16-2916).

\section{Conflict of interests}

est.

The authors declare no conflict of inter-

\section{REFERENCES}

Alexander, A. (2008). Media and the Family. $V$ The Handbook of Children, Media and Development, ed. Calvert, S. L. in Barbara J. Wilson, B. J., 614. Chichester, VB: Blackwell Publishing. http://dx.doi.org/10.1002/9781444302752.ch6

Arango, C. M., Parra, D. C., Gómez, L. F., Lema, L., Lobelo, F. \& Ekelund, U. (2014). Screen time, cardiorespiratory fitness and adiposity among school-age children from Monteria, Colombia. Journal of Science and Medicine in Sport 17(5). Sports Medicine Australia: 491-95. https://doi. org/10.1016/j.jsams.2013.09.010

Bandura, A. (1977). Social Learning Theory. Englewood Hills, New York: Prentice Hall.

Bandura, A. (1994). Social cognitive theory of mass communication.(Ed. J. Bryant ve D. Zillman, Media effects: Advances in theory and research (s. 61-90).

Bandura, A., Ross, D., \& Ross, S. A. (1961). Transmission of aggression through imitation of aggressive models. The Journal of Abnormal and Social Psychology, 63(3), 575-582. http://dx.doi. org $/ 10.1037 / \mathrm{h} 0045925$

Baran, S. J., \& Davis, D. K. (2006). Mass communication theory: foundations, ferment and future. California: Thomson Wadsworth

Böcking, S., \& Böcking, T. (2009). Parental Mediation of Television: Test of a German-speaking scale and findings on the impact of parental attitudes, sociodemographic and family factors in German-speaking Switzerland. Journal of Children and Media, 3(3), 286-302. https://doi. org/10.1080/17482790902999959

Chakroff, J. L. \& Nathanson, A. A. (2008). Parent and School Interventions: Mediation and Media Literacy. In The Handbook of Children, Media and Development, ed. Calvert, S. L. \& Wilson, B. J. first, 614. Chichester, VB: Blackwell Publishing. http://dx.doi.org/10.1002/9781444302752. $\operatorname{ch} 24$

Craig, R. T. (1999). Communication theory as a field. Communication theory, 9(2), 119-161. https:// doi.org/10.1111/j.1468-2885.1999.tb00355.x

Ferguson, C. J. (2014). Adolescents, crime, and the media. New York City, NY: Springer. https://doi. org/10.1007/978-1-4614-6741-0

Gerbner, G., L. Gross, M. M. \&. Signorielli, N. (1994). Growing up with Television: The Cultivation Perspective. In Media Effects: Advances in Theory and Research, ed. Bryant, J. \& D. Zillman, 17-41. Mahwah, New York: Lawrence Erlbaum.

Kalin, A. (2004). Vloga medijev pri sodobnem pouku in presojanje njihove učinkovitosti (The role of media in modern lessons and the judgment of their efficiency). Pedagoška obzorja 19(3-4). http://www.pedagoska-obzorja.si/revija/Vsebine/povzetki/po04-3-4.html\#2004-3-10

Livingstone, S. (2007). Do the media harm children? Reflections on new approaches to an old problem. Journal of children and media, 1(1), 5-14. https://doi.org/10.1080/17482790601005009

Notten, N., Kraaykamp, G., \& Tolsma, J. (2013). Parents, Television and Children's Weight Status: On lasting effects of parental television socialization in the Netherlands. Journal of Children and Media, 7(2), 235-252. https://doi.org/10.10 80/17482798.2012.712917

Ofcom, U. K. (2014). Children and parents: Media use and attitudes report. http://stakeholders.ofcom. org.uk/binaries/research/media-literacy/mediause-attitudes-14/Childrens 2014 Report.pdf

Paus-Hasebrink, I., Bauwens, J., Dürager, A. E., \& Ponte, C. (2013). Exploring types of parent-child relationship and Internet use across Europe. Journal of Children and Media, 7(1), 114-132. https://doi.org/10.1080/17482798.2012.739807

Rideout, V. J., Foehr, U. G., \& Roberts, D. F. (2010). Generation M 2: Media in the Lives of 8-to 18-Year-Olds. Henry J. Kaiser Family Foundation. https://eric.ed.gov/?id=ED527859

Roberts, D. F., Foehr, U. G., \& Rideout, V. (2005). Generation M: Media in the lives of $8-18$ year-olds. Menlo Park, CA: Kaiser Family Foundation.

Robinson, T. N., Banda, J. A., Hale, L., Lu, A. S., Fleming-Milici, F., Calvert, S. L., \& Wartella, E. (2017). Screen media exposure and obesity in children and adolescents. Pediatrics, 140(Supplement 2), S97-S101. https://doi.org/10.1542/ peds.2016-1758K

Rutherford, L., Brown, J. E., Skouteris, H., Fuller-Tyszkiewicz, M., \& Bittman, M. (2015). Screen media, parenting practices, and the family environment in Australia: A longitudinal study of young children's media use, lifestyles, and outcomes for healthy weight. Journal of Children and Media, 9(1), 22-39. https://doi.org/10.1080/174827 98.2015.997101

Schaan, V. K., \& Melzer, A. (2015). Parental mediation of children's television and video game use in Germany: Active and embedded in family processes. Journal of Children and Media, 9(1), 58-76. https://doi.org/10.1080/17482798.2015. 997108

Scherr, S., Mares, M. L., Bartsch, A., \& Götz, M. (2018). On the relevance of parents and TV as socializers of 6-19 year-olds' expressions of emotion: representative data from Germany. Journal of Children and Media, 12(1), 33-50. https://doi.or $\mathrm{g} / 10.1080 / 17482798.2017 .1365738$

Sigman, A. (2012). The Impact of Screen Media on Children: A Eurovision for Parliament. In Improving the Quality of Childhood in Europe, uredil Christopher Clouder, Belinda Heys, Michiel Matthes, in Patrice Sullivan, 3: 88-121. Brighton: European Council for Steiner Waldorf 
Bojan Macuh et al. (2018) - Media exposure and education of first to six grade children from Slovenia parent opinions International Journal of Cognitive Research in Science, Engineering and Education (IJCRSEE), 6(3), 49-57

Education.

Valkenburg, P. M. \& Piotrowski, J. T. (2017). Plugged in: How Media Attract and Affect Youth. New Haven in London: Yale University Press. https:// doi.org/10.1080/17482798.2017.1341116 